\title{
Ureaplasma parvum genotype, combined vaginal colonisation with Candida albicans, and spontaneous preterm birth in an Australian cohort of pregnant women
}

Matthew S. Payne ${ }^{1 *}$, Demelza J. Ireland ${ }^{1}$, Rory Watts ${ }^{1}$, Elizabeth A. Nathan ${ }^{1,2}$, Lucy L. Furfaro ${ }^{1}$, Matthew W. Kemp ${ }^{1}$, Jeffrey A. Keelan ${ }^{1}$ and John P. Newnham ${ }^{1}$

\begin{abstract}
Background: Detection of Ureaplasma, Mycoplasma and Candida spp. in the vagina during pregnancy has previously been associated with preterm birth (PTB). However, the prevalence of these microorganisms and the associated obstetric risks (likely to be population-specific) have not been determined in Australian women; furthermore, in the case of Ureaplasma spp., very few studies have attempted characterisation at the species level and none have examined genotype/serovar status to further refine risk assessment.

Methods: In order to address these issues we sampled the vaginal fluid of 191 pregnant Australian women at three time points in pregnancy. Culture methods were used for detection of Ureaplasma spp. and Candida spp., and real-time PCR was used for speciation of U. parvum and U. urealyticum, non-albicans Candida spp., Mycoplasma hominis and Mycoplasma genitalium. High-resolution melt PCR was used to genotype U. parvum. Data on various lifestyle factors (including sex during pregnancy and smoking), antimicrobial use and pregnancy outcome were collected on all participants. Chi-square tests were used to assess the association of vaginal microorganisms with PTB.

Results: Detection of Ureaplasma spp. was higher among spontaneous PTB cases, specifically in the presence of U. parvum [77\% preterm (95\% confidence interval (Cl) 50-100\%) vs. $36 \%$ term (Cl: 29-43\%), $p=0.004$ ], but not $U$. urealyticum. The association with PTB strengthened when U. parvum genotype SV6 was detected (54\% preterm (Cl: $22-85 \%)$ vs. $15 \%$ term (Cl: 10-20\%), $p=0.002)$; this genotype was also present in $80 \%(4 / 5)$ of cases of PTB $<34$ weeks gestation. When present with Candida albicans in the same sample, the association with PTB remained strong for both U. parvum [46\% preterm (Cl: 15-78 \%) vs. $13 \%$ term (Cl: 8-18\%), $p=0.005$ ] and U. parvum genotype SV6 [39\% preterm (Cl: 8-69 \%) vs. $7 \%$ term (Cl: 3-11\%), $p=0.003]$. With the exception of Candida glabrata, vaginal colonisation status for all organisms was stable throughout pregnancy. Smoking significantly increased the likelihood of detection of all target organisms.

Conclusions: These data suggest that the presence of different species and serovars of Ureaplasma spp. in the vagina confers an increased risk of spontaneous PTB, findings which may be useful in risk assessment for identifying women who would benefit from antimicrobial treatment.
\end{abstract}

Keywords: Ureaplasma spp, Mycoplasma spp, Candida spp, Genotyping, Vagina, Preterm birth

\footnotetext{
* Correspondence: matthew.payne@uwa.edu.au

'School of Women's and Infants' Health, University of Western Australia, 2nd

Floor, Block A, King Edward Memorial Hospital, Subiaco, WA 6008, Australia

Full list of author information is available at the end of the article
} 


\section{Background}

The role of human genital Ureaplasmas (Ureaplasma parvum and Ureaplasma urealyticum) and Mycoplasmas (Mycoplasma hominis and Mycoplasma genitalium) in preterm birth (PTB) has been a contentious topic that has resulted in considerable research over the past two decades. A recent review article by Capoccia et al. [1], summarizing the bulk of this research effort (with the exception of $M$. genitalium), showed that the majority of studies with defined case/control subjects found an association with negative pregnancy outcomes, especially for Ureaplasma spp. For $M$. hominis, this association appeared to be increased when detected alongside Ureaplasma spp. [1]. M. genitalium, however, is more commonly associated with pelvic inflammatory disease [2] and has also been linked to bacterial vaginosis (BV) [3]. Vaginal colonisation by Candida spp., a common yeast synonymous with vaginal thrush, has also been associated with PTB risk [4-7].

However, it is still unclear why some women who are asymptomatically colonised with these organisms have pregnancies that deliver preterm while others deliver at term; possible explanations include interactions with other microorganisms and inflammatory modulators, the timing and duration of colonisation, differences in virulence between species/strains, and eradication or exacerbation via maternal immune responses. With respect to Ureaplasma spp., very few studies have ever attempted to refine the data beyond the genus level, despite evidence that numerous other Ureaplasmaassociated disease phenotypes are differentially associated with $U$. urealyticum and not $U$. parvum [8-12]. Further to this, to the best of our knowledge, no studies have ever looked at the relationship that may exist between PTB and the presence of specific Ureaplasma spp. genotypes (serovars). In addition, few studies have looked at the effect of combined colonisation with these organisms, with most studies instead focusing on either Ureaplasma spp. and M. hominis (and not $M$. genitalium) or Candida spp.

PTB is now recognised as the leading cause of death in children under the age of 5 years in the developed world [13], with intrauterine infection being causally associated with $\sim 40 \%$ of all PTBs [14]. In particular, the births of the earliest gestational ages, which are associated with the greatest mortality and morbidity, are much more likely to be the consequence of intrauterine infection and/or inflammation (up to $80 \%$ ). There is, therefore, a need to be able to predict which women are at a high risk of PTB, based on factors other than previous clinical history alone, so that appropriate treatment may be provided to those who would benefit. This is especially relevant for women in their first pregnancy. Despite the body of research that has been conducted into the presence and significance of genital Ureaplasma,
Mycoplasma and Candida spp. colonisation during pregnancy, there is very little information available on the relationship between specific lifestyle practices, such as smoking and sexual activity, and vaginal colonisation. However, it has been well established that tobacco use increases susceptibility to bacterial infection [15] and a strong association has been documented between smoking and BV [16-19]. Furthermore, some genital Ureaplasma and Mycoplasma spp. are deemed to be sexually transmitted infections [20].

In addition, the vast majority of previous studies that have looked at genital Ureaplasma, Mycoplasma and Candida spp., have focused on collection of clinical samples at a single time point. This approach provides no data on the colonisation dynamics of a particular organism and this is likely to be of significance in terms of implementing diagnostic assays for the detection of women at risk of PTB. It is highly likely that all of the above information combined, will not only increase our understanding of these organisms during pregnancy, but importantly, will allow us to establish useful microbial biomarkers. These, combined with patient-specific qualitative data, will improve our ability to predict women at an increased risk of PTB who would benefit from antimicrobial treatment. Due to previous descriptions of variation in the vaginal microbiota as a result of ethnic, cultural and social factors [21], it is likely that microbial colonisation status and PTB risk are strongly population-dependent.

The aims of this study, therefore, were to document the presence of $U$. parvum (including genotype analysis), $U$. urealyticum, C. albicans, C. glabrata, other non-albicans Candida spp., M. hominis and M. genitalium in the vagina of a cohort of asymptomatic pregnant Australian women at three time points during pregnancy, and to examine any association between their microbiological characteristics, a range of lifestyle factors, and risk of PTB.

\section{Methods \\ Subjects}

The study consisted of 206 low-risk pregnant women recruited from King Edward Memorial Hospital (KEMH), Perth, Western Australia. Fifteen cases withdrew from the study or were lost to follow-up, leaving 191 for analysis. The study was approved by the Human Research Ethics Committee of the Western Australian Department of Health, Women and Newborn Health Service (2056/EW).

\section{Inclusion and exclusion criteria}

Women with a singleton pregnancy were eligible for inclusion if they were aged 18-40 years, able to speak and read English and were pregnant within the first or second trimester. 
Women were excluded from the study if they were deemed to be at a high risk of PTB (one or more previous PTBs) and/or other pregnancy complications such as preeclampsia. Other exclusion criteria included current use of antifungals, tetracycline and/or macrolide antibiotics, current diagnosis of a urinary tract infection, and history of recurrent vaginal thrush.

\section{Questionnaires}

Upon recruitment to the study and at each subsequent sampling point, women were invited to complete a deidentified medical/lifestyle questionnaire in a private setting. The questionnaire first inquired about medications currently used (antibiotic/natural/probiotic) and past diagnoses of urinary tract infections/vaginal thrush. Information regarding current and previous smoking and/ or alcohol use was sought as 'yes or no', and subsequently followed by questions to quantify the number of cigarettes smoked/standard drinks consumed each day as appropriate. The average number of episodes of sexual intercourse per week during pregnancy was recorded.

\section{Pregnancy outcome data}

Pregnancy outcome data from the hospital's electronic medical records were accessed by experienced research midwives and coded after completion of the pregnancy.

\section{Sample collection}

Written informed consent was obtained by the attending midwife prior to enrolment in the study. This included consenting to publication of any data produced by the study. Participants provided two self-collected vaginal swabs (Copan Diagnostics, Murrieta, CA, USA) at recruitment (median 21 week, range 13-26 weeks gestational age [GA]), 28 weeks GA (median 29, range 24-38 weeks) and $\sim 36$ weeks GA (median 36, range 32-40 week). The first swab was employed for detection of Ureaplasma and Mycoplasma spp. and the second for detection of Candida spp. Detailed verbal, written and pictorial instructions were provided to all women in an attempt to standardise the swab collection process. Briefly, while wearing gloves, participants inserted the swab $5 \mathrm{~cm}$ into their vagina and gently rotated this for $20 \mathrm{~s}$, ensuring the walls of the vagina came into contact with the swab. Swabs were then immediately placed into a collection tube containing either $1 \mathrm{~mL}$ UTM media (Ureaplasma and Mycoplasma spp.) (Copan Diagnostics) or $2 \mathrm{~mL}$ of CAT media (Candida spp.) (Copan Diagnostics), snapped at the midstem breakpoint, capped and stored at $4{ }^{\circ} \mathrm{C}$. All samples were transported to the laboratory on ice for culture within $24 \mathrm{~h}$ of collection.

\section{Detection of Ureaplasma spp. \\ Culture}

UTM tubes were vortexed for $10 \mathrm{~s}$ to release all cells from swabs. Swabs were subsequently pressed against the tube wall to release all free liquid and then discarded. Two hundred microliters of sample was added to $1.8 \mathrm{~mL}$ of $10 \mathrm{~B}$ broth (Melbourne University Media Preparation Unit) and incubated for $48 \mathrm{~h}$ at $37^{\circ} \mathrm{C}, 5 \%$ $\mathrm{CO}_{2}, 2 \% \mathrm{O}_{2}$. The remaining volume of sample was transferred to a $2 \mathrm{~mL}$ microfuge tube and frozen at $-80{ }^{\circ} \mathrm{C}$ until DNA extraction.

Positive cultures, indicated by a $\mathrm{pH}$-associated colour change (yellow $>$ pink), were immediately transferred to $2 \mathrm{~mL}$ microfuge tubes and frozen at $-80^{\circ} \mathrm{C}$.

\section{DNA extraction}

DNA was extracted from $250 \mu \mathrm{L}$ of UTM swab eluate using the Siemens Sample Preparation Kit 1.0 (Siemens, Munich, Germany) on an automated Kingfisher Duo extraction platform (Thermo Fisher Scientific Inc. MA, USA) as per manufacturer's instructions. All extracts were eluted in a final volume of $100 \mu \mathrm{L}$ of elution buffer (Siemens). A positive extraction control consisting of approximately 250 colour changing units (CCU) each of $U$. parvum and $U$. urealyticum was included in all runs.

\section{Real-time $P C R$}

In addition to culture, Ureaplasma spp. DNA was detected from vaginal swabs using real-time PCR. Vaginal swab DNA was screened using an assay targeting the urease gene of $U$. parvum and $U$. urealyticum, as described by Yi et al. [22], adapted for use on a ViiA7 realtime PCR system (Life Technologies, Carlsbad, CA, USA). Reaction mixtures (final concentration) consisted of 1X Taqman FAST Advanced Master Mix (Life Technologies), $0.9 \mu \mathrm{M}$ primers UU1613F and UU1524R (Life Technologies), $0.25 \mu \mathrm{M}$ probes UU-parvo (FAM) and UU-T960 (VIC) (Life Technologies), $5 \mu \mathrm{L}$ of template DNA and nuclease-free water (Ambion, Life Technologies) to a final volume of $20 \mu \mathrm{L}$. PCR cycling conditions consisted of an initial denaturation/Taq activation at $95{ }^{\circ} \mathrm{C}$ for $20 \mathrm{~s}$, followed by 40 quantification cycles of $95^{\circ} \mathrm{C}$ for $1 \mathrm{~s}$ and $60{ }^{\circ} \mathrm{C}$ for $20 \mathrm{~s}$ (data acquiring). Positive standards were included in each run.

\section{High-resolution melt $P C R$}

Samples that were positive for $U$. parvum DNA were genotyped and classified as either serovar (SV) one, SV3, SV6 or SV14 using our previously described high resolution melt (HRM) PCR assay targeting the multiple-banded antigen gene [23] on a ViiA7 real-time PCR system (Life Technologies). Reaction mixtures (final concentration) consisted of 1X Amplitaq Gold 360 buffer (Life Technologies), $1.5 \mathrm{mM}$ $\mathrm{MgCl}_{2}$ (Life Technologies), $200 \mu \mathrm{M}$ of each dNTP 
(Life Technologies), $0.3 \mu \mathrm{M}$ primers UPHRM-F and UPHRM-R (Life Technologies), 1X MeltDoctor HRM dye (Life Technologies), Amplitaq Gold 360 DNA polymerase $(0.1 \mathrm{U} / \mu \mathrm{L})$ (Life Technologies), $10 \mu \mathrm{L}$ of template DNA and nuclease-free water (Ambion, Life Technologies) to a final volume of $20 \mu \mathrm{L}$. PCR cycling conditions consisted of an initial denaturation/Taq activation at $95{ }^{\circ} \mathrm{C}$ for $10 \mathrm{~min}$, followed by 40 cycles of $95{ }^{\circ} \mathrm{C}$ for $15 \mathrm{~s}$ and $60{ }^{\circ} \mathrm{C}$ for $1 \mathrm{~min}$ (data acquiring). To provide data on $U$. parvum serovar status, amplicons were subsequently subject to a HRM step where the temperature was raised to $95{ }^{\circ} \mathrm{C}$ for $10 \mathrm{~s}$ and then lowered to $60{ }^{\circ} \mathrm{C}$ for $1 \mathrm{~min}$. The temperature was then raised to $95{ }^{\circ} \mathrm{C}$ at a rate of $0.025{ }^{\circ} \mathrm{C} / \mathrm{s}$ (continuous data acquisition), held at $95{ }^{\circ} \mathrm{C}$ for $15 \mathrm{~s}$ and then lowered to $60{ }^{\circ} \mathrm{C}$ for $15 \mathrm{~s}$. HRM profiles were analysed using ViiA7 real-time PCR system software v1.2.1 (Life Technologies). All samples were run in duplicate and positive standards of $U$. parvum SV1, SV3, SV6 and SV14 were included in each run.

\section{Sequencing}

Following HRM analysis, samples that produced nonstandard melt curve patterns were subject to DNA sequencing. PCR amplicons were generated using the same HRM primer set on a Veriti PCR thermocycler (Life Technologies). Reaction mixtures (final concentration) consisted of 1X Amplitaq Gold 360 buffer (Life Technologies), $2.0 \mathrm{mM} \mathrm{MgCl} 2$ (Life Technologies), $200 \mu \mathrm{M}$ of each dNTP (Life Technologies), $0.5 \mu \mathrm{M}$ primers UPHRM-F and UPHRM-R (Life Technologies), Amplitaq Gold 360 DNA polymerase (1.25U) (Life Technologies), $5 \mu \mathrm{L}$ of template DNA and nuclease-free water (Ambion, Life Technologies) to a final volume of $50 \mu \mathrm{L}$. PCR cycling conditions consisted of an initial denaturation/Taq activation at $95{ }^{\circ} \mathrm{C}$ for $10 \mathrm{~min}$, followed by 40 cycles of $95{ }^{\circ} \mathrm{C}$ for $15 \mathrm{~s}, 56{ }^{\circ} \mathrm{C}$ for $30 \mathrm{~s}$ and $72{ }^{\circ} \mathrm{C}$ for $45 \mathrm{~s}$. A final extension step of $72{ }^{\circ} \mathrm{C}$ for 7 min was also included.

PCR amplicons were checked for size (305 bp) on a $1.5 \%$ agarose gel stained with Gel Red (Biotium) and subsequently purified using a QIAquick PCR purification kit (QIAGEN) as per manufacturer's instructions. Purified DNA fragments were sequenced using Big Dye version 3.1 chemistry (Applied Biosystems) and post-cleaned using SPRI. Fragments were separated on a 3730xI DNA Analyser using a 96-capillary array (Applied Biosystems) at the Australian Genome Research Facility (Perth, Western Australia).

\section{Detection of Mycoplasma spp. DNA extraction}

DNA was extracted from $250 \mu \mathrm{L}$ of UTM swab eluate as described above.

\section{Real-time PCR}

Mycoplasma hominis $M$. hominis DNA was detected in vaginal swabs using real-time PCR. DNA samples were screened using an assay targeting the yidC gene of $M$. hominis as described by Ferandon et al. [24], adapted for use on a ViiA7 real-time PCR system (Life Technologies). Reaction mixtures (final concentration) consisted of 1X Taqman FAST Advanced Master Mix (Life Technologies), $0.9 \mu \mathrm{M}$ primers MHyidCfwd and MHyidCrev (Life Technologies), $0.25 \mu \mathrm{M}$ probe MHyidC (FAM) (Life Technologies), $5 \mu \mathrm{L}$ of template DNA and nuclease-free water (Ambion, Life Technologies) to a final volume of $20 \mu \mathrm{L}$. PCR cycling conditions were as described for Ureaplasma spp. A positive standard was included in each run.

Mycoplasma genitalium M. genitalium DNA was detected in vaginal swabs using real-time PCR. DNA samples were screened using an assay targeting the $\mathrm{MgPa}$ gene of $M$. genitalium as described by Jensen et al. [25], adapted for use on a ViiA7 real-time PCR system (Life Technologies). Reaction mixtures (final concentration) consisted of 1X Taqman FAST Advanced Master Mix (Life Technologies), $0.9 \mu \mathrm{M}$ primers $\mathrm{MgPa}-355 \mathrm{~F}$ and MgPa-432R (Life Technologies), $0.25 \mu \mathrm{M}$ probe MgPa380 (VIC) (Life Technologies), 7.9 $\mu \mathrm{L}$ of template DNA and nuclease-free water (Ambion, Life Technologies) to a final volume of $20 \mu \mathrm{L}$. PCR cycling conditions consisted of an initial denaturation/Taq activation at $95{ }^{\circ} \mathrm{C}$ for $20 \mathrm{~s}$, followed by 50 quantification cycles of $95{ }^{\circ} \mathrm{C}$ for $1 \mathrm{~s}$ and $60{ }^{\circ} \mathrm{C}$ for $20 \mathrm{~s}$ (data acquiring). Positive standards were included in each run.

\section{Detection of Candida spp. \\ Culture}

CAT tubes were vortexed for $10 \mathrm{~s}$ to release all cells from swabs. Swabs were subsequently pressed against the tube wall to release all free liquid and then disposed of. One millilter of sample was transferred to a $2 \mathrm{~mL}$ microfuge tube and frozen at $-80{ }^{\circ} \mathrm{C}$ until DNA extraction. The remaining sample (approximately $900 \mu \mathrm{L}$ ) was incubated at $37{ }^{\circ} \mathrm{C}$ for $24 \mathrm{~h}$ to enrich for low cell titres of Candida spp. Following incubation, two $10 \mu \mathrm{L}$ loops of sample were plated onto Candida Brilliance agar (Oxoid, Thebarton, South Australia, Australia) and incubated at $37^{\circ} \mathrm{C}$ for $72 \mathrm{~h}$.

Positive cultures on Candida Brilliance agar (Oxoid) were classified as follows: Green colonies = C. albicans; pink/ yellow $/$ beige $/$ brown $\quad$ colonies $=$ non-albicans $\quad$ Candida spp. All positive cultures were re-plated for purity and following incubation, pure cultures were re-suspended in $2 \mathrm{~mL}$ of Sabaraud-Dextrose broth (Oxoid) and frozen at $-80^{\circ} \mathrm{C}$. 


\section{DNA extraction}

DNA was extracted from $250 \mu \mathrm{L}$ of pure Candida sp. isolate broth resuspension as described above.

\section{Real-time $P C R$}

To confirm the identification of non-albicans Candida spp. isolated using Candida Brilliance agar, a multiplex real-time PCR assay targeting the RNase P RNA (RPR) gene of Candida sp. and C. glabrata was used. Primer and probe designs were similar to that of Innings et al. [26], but were optimised for use on a ViiA7 real-time PCR system (Life Technologies). Reaction mixtures (final concentration) consisted of 1X Taqman FAST Advanced Master Mix (Life Technologies), $0.9 \mu \mathrm{M}$ primers CAND-CR1F (5' CGG GTGGGAAATTCGGT 3'), CAND-CR5R (5' CAATGAT CGGTATCGGGT 3'), GLA-F (5' TGGCTCACACAC TTTGTCACTTT 3') and GLAR (5' ACCTCGCCTCAC ACCAATG 3') (Life Technologies), $0.25 \mu \mathrm{M}$ probes ALLCAN (NED-TTCGCATATTGCACTMAAYAGC-MGB) and GLA (VIC-AACCTGCCATTTCCGCTCCCTTAA GA-TAMRA) (Life Technologies), $5 \mu \mathrm{L}$ of template DNA and nuclease-free water (Ambion, Life Technologies) to a final volume of $20 \mu \mathrm{L}$. PCR cycling conditions were as described above for Ureaplasma spp.

\section{Statistical analyses}

Data were summarised using frequency distributions for categorical data, and median, interquartile range and range for continuous data. Categorical outcomes were compared using Chi-square and Fisher's exact tests, and continuous outcomes compared using Mann-Whitney tests. All analyses were conducted on detection of microbes at recruitment, due to the relatively stable colonisation levels throughout pregnancy. SPSS Version 20.0 (Armonk, NY: IBM Corp) statistical software was used for data analysis. $P$-values $<0.05$ were considered statistically significant.

\section{Results}

\section{Subjects}

206 women in total were recruited to the study. From these, 15 withdrew or were lost to follow-up. Demographic/birth and lifestyle characteristics of the 191 women that formed the final study cohort are provided below (Table 1). The overall PTB rate ( $<37$ weeks GA) was $9 \%$, which included 13 spontaneous births and four births that required labour induction or caesarean delivery for maternal or fetal indications. These four births were excluded in the comparison of microorganisms between preterm and term births. There were six births (five spontaneous) <34 weeks GA (3\%) and two births with a birth weight $<1500 \mathrm{~g}(1 \%)$.
Table 1 Demographic, birth and lifestyle characteristics of women in the study ${ }^{a}$

\begin{tabular}{|c|c|}
\hline Demographic and birth & $n=191$ \\
\hline Maternal age (y) & $30(26-33 ; 18-43)$ \\
\hline Caucasian & $119(62 \%)$ \\
\hline GA at birth & $39(38-40 ; 26-42)$ \\
\hline GA $<37$ weeks & 17 (9 \%) \\
\hline Birthweight (g) & $3435(3080-3733 ; 690-4794)$ \\
\hline Gender male & $92(48 \%)$ \\
\hline Lifestyle and medication & $n=189$ \\
\hline $\begin{array}{l}\text { Current antibiotic, antifungal or } \\
\text { probiotic medication }\end{array}$ & $8(4 \%)$ \\
\hline UTI diagnosis ever & 75 (40 \%) \\
\hline Thrush diagnosis ever & $91(48 \%)$ \\
\hline Thrush $>2$ times & $12(13 \%)$ \\
\hline Current smoker & $21(11 \%)$ \\
\hline Smoke >10/day & $5(3 \%)$ \\
\hline Previous smoker & $50(27 \%)$ \\
\hline Smoke >10-20/day & $13(7 \%)$ \\
\hline Smoke $>20 /$ day & $5(3 \%)$ \\
\hline Current alcohol & $4(2 \%)$ \\
\hline$\geq 5$ drinks/week & $1(0.5 \%)$ \\
\hline Previous alcohol & $108(57 \%)$ \\
\hline$<1$ drink/week & 17 (9 \%) \\
\hline 1-4 drinks/week & $64(34 \%)$ \\
\hline$\geq 5$ drinks per wk & $18(9 \%)$ \\
\hline \multicolumn{2}{|l|}{ Current sexual intercourse } \\
\hline$<1$ week & $42(23 \%)$ \\
\hline 1-2 times/week & $96(52 \%)$ \\
\hline$\geq 3$ times/week & $48(26 \%)$ \\
\hline
\end{tabular}

y years, GA gestational age, $w k$ weeks, $g$ grams

${ }^{\mathrm{a}}$ Data represents median (interquartile range; range) or $N(\%)$, as appropriate

\section{Detection of vaginal Ureaplasma, Mycoplasma and Candida spp. during pregnancy}

Vaginal detection rates for Ureaplasma spp., Mycoplasma spp. and Candida spp. varied substantially at both the genus and species level (Table 2). Ureaplasma spp. were the most common of the three organisms detected, present in 44-48\% of women over the three sampling points. Within this genus, $U$. parvum was the most common species detected, 3-4 times more prevalent than $U$. urealyticum (Table 2 ).

Candida spp. were the second most common organism detected, present in 34-38 \% of women. Within this genus, $C$. albicans was by far the most common species detected, 6-25 and 10-24 times more prevalent than $C$. glabrata and non-albicans/non-glabrata Candida spp., respectively (Table 2 ). 
Table 2 Detection rates for vaginal Ureaplasma, Mycoplasma and Candida spp. during pregnancy ${ }^{a}$

\begin{tabular}{llll}
\hline Organisms & $\begin{array}{l}\text { Time-point } 1 \\
(n=191)\end{array}$ & $\begin{array}{l}\text { Time-point } 2 \\
(n=154)\end{array}$ & $\begin{array}{l}\text { Time-point } 3 \\
(n=152)\end{array}$ \\
\hline Gestation at sampling $(w k)^{b}$ & $21(13-26)$ & $29(24-38)$ & $36(32-40)$ \\
Ureaplasma spp. & $91(48 \%)$ & $74(48 \%)$ & $67(44 \%)$ \\
$\quad$ U. parvum & $74(39 \%)$ & $63(41 \%)$ & $53(35 \%)$ \\
SV1 & $11(5.8 \%)$ & $10(6.5 \%)$ & $10(6.6 \%)$ \\
SV3 & $27(14.1 \%)$ & $20(13 \%)$ & $19(12.5 \%)$ \\
SV6 & $31(16.2 \%)$ & $24(15.6 \%)$ & $18(11.8 \%)$ \\
SV6.1 & $1(0.5 \%)$ & $1(0.6 \%)$ & $1(0.7 \%)$ \\
SV14 & $0(0 \%)$ & $0(0 \%)$ & $0(0 \%)$ \\
Mixed & $2(1 \%)$ & $2(1.3 \%)$ & $3(2 \%)$ \\
Too weak to call & $0(0 \%)$ & $3(1.9 \%)$ & $0(0 \%)$ \\
No amplification & $2(1 \%)^{c}$ & $2(1.3 \%)^{c}$ & $2(1.3 \%)^{c}$ \\
U. urealyticum & $25(13 \%)$ & $15(10 \%)$ & $16(11 \%)$ \\
Candida spp. & $73(38 \%)$ & $53(34 \%)$ & $52(34 \%)$ \\
C. albicans & $63(33 \%)$ & $50(33 \%)$ & $48(32 \%)$ \\
C. glabrata & $10(5 \%)$ & $2(1 \%)$ & $3(2 \%)$ \\
Non-albicans/ & $5(3 \%)$ & $5(3 \%)$ & $2(1 \%)$ \\
non-glabrata & & & $4(3 \%)$ \\
Candida spp. & $21(11 \%)$ & $12(8 \%)$ & $16(11 \%)$ \\
M. hominis & $6(3 \%)$ & $3(2 \%)$ & $4 \%$ genitalium \\
M. & & &
\end{tabular}

Due to variations in sample compliance, apparent reductions or increases in genotypes over the three time points are not indicative of genotype stability brepresents median, range

'Same study participants

Detection rates for $M$. hominis and $M$. genitalium were much lower than for Ureaplasma spp. and Candida spp. M. hominis detection rates ranged from 8 to $11 \%$ over the three sampling points, whilst for M. genitalium, rates ranged from 2 to $3 \%$ (Table 2).

\section{Comparison of culture and real-time PCR for detection of Ureaplasma spp.}

Detection rates of Ureaplasma spp. by 10B broth culture at $37{ }^{\circ} \mathrm{C}\left(5 \% \mathrm{CO}_{2}, 95 \% \mathrm{~N}_{2}\right)$ were almost identical to detection rates by real-time PCR. Concordance between the two techniques was 99, 100 and $100 \%$ over the three time-points, respectively.

\section{High-resolution melt PCR genotyping of $U$. parvum}

HRM PCR was able to resolve singular $U$. parvum genotypes in $91 \%$ of colonised clinical samples. U. parvum genotype SV6 was the most common detected, closely followed by SV3, SV1 and SV6.1, respectively. No cases of genotype SV14 were found (Table 2). An additional $3 \%$ of cases were resolved to the 'mixed' genotype level, suggesting the presence of two or more $U$. parvum genotypes within the same sample. There was also a small number of cases where either amplification was too weak to produce a melt curve sufficient for genotype discrimination (1\%) or no amplification was produced whatsoever (3\%). In addition, for one study participant, all three samples produced slightly different HRM curves, which upon DNA sequencing, showed four unique nucleotide polymorphisms within the targeted region of the multiple-banded antigen gene, not indicative of any of the four characterised $U$. parvum genotypes. The sequence was most closely matched to genotype SV6, and as a result was deemed genotype SV6.1.

\section{Vaginal colonisation dynamics}

Of the 191 study participants, 134 provided samples at all three time points. In these women, detection rates for all organisms showed minimal variance over the duration of the study (Fig. 1). M. genitalium (1.5\% at all three points) had the lowest variance of all organisms detected, followed by $U$. parvum (36.6-37.3\%), U. urealyticum (9.7-11.2 \%) and non-albicans/non-glabrata Candida spp. (0.7-2.2\%), C. albicans (32.1-34.3\%) and M. hominis (9-11.2 \%), and last, C. glabrata (1.5-5.2\%). These results are inclusive of one case where $U$. par$\nu u m / U$. urealyticum was detected at recruitment sampling, after which $U$. urealyticum was not detected again in subsequent samples.

Similarly, there was very little variance in $U$. parvum genotype detection at any of the three time points. In nearly all cases, the genotype detected at recruitment was maintained throughout the second and third time points. The only exceptions were in one case where a participant colonised by $U$. parvum genotype SV6 at recruitment showed a mixed genotype profile at the later time points, and in another case where mixed genotype

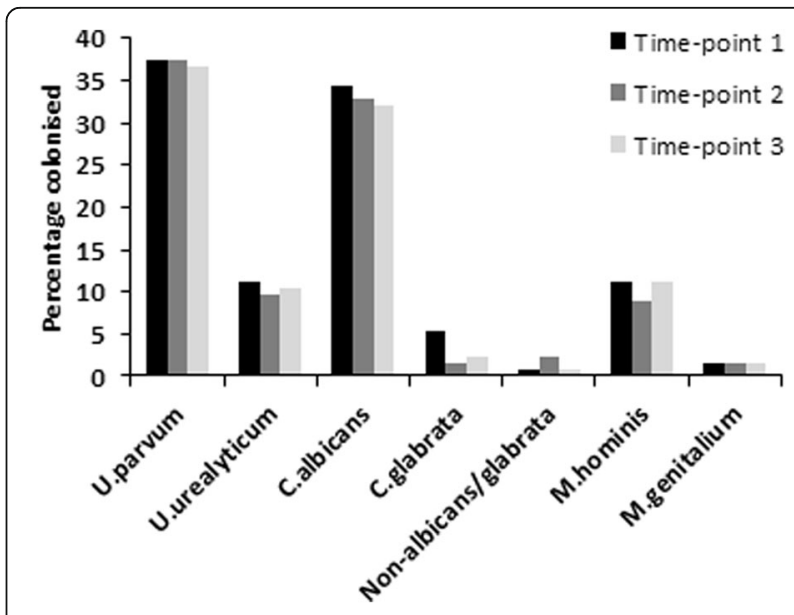

Fig. 1 Prevalence of Ureaplasma, Candida and Mycoplasma spp. in vaginal swab samples from 134 women with three completed samples taken over the course of the pregnancy. Solid black, sample time-point 1; dark grey, sample time-point 2; light grey, sample time-point 3 
profiles were detected at all three time points. This made it impossible to be certain that the same combination of genotypes was present in each instance, due to the limitations of the HRM assay. There were also an additional two instances where the HRM assay failed to generate sufficient amplification of the second sample to allow accurate genotype discrimination. However, in both of these cases, the first and third sample genotype identifications were concordant.

\section{Association between pharmaceutical \& lifestyle factors and detection of organisms at recruitment}

Based upon answers provided by 189 study participants at recruitment (Table 3), Ureaplasma spp. and Mycoplasma spp. were detected more frequently in women who previously smoked (Ureaplasma spp. $-37 \%$ present vs. $17 \%$ absent, $p=0.002$; and Mycoplasma spp. $-44 \%$ present vs. $24 \%$ absent, $p=0.036$ ), and in women who had sexual intercourse $\geq 3$ times per week during pregnancy (Ureaplasma spp. $-35 \%$ present vs. $18 \%$ absent, $p=0.018$; and Mycoplasma spp. $-56 \%$ present vs. $21 \%$ absent, $p=0.001$ ).

Candida spp. were detected more frequently in women who continued to smoke during their pregnancy (Candida spp. $-18 \%$ present vs. $7 \%$ absent, $p=0.020$ ).

\section{Association between vaginal microbial colonisation and spontaneous preterm birth \\ Spontaneous preterm birth $<37$ weeks $G A$}

The overall microbial characteristics of vaginal samples collected during the study are provided in Table 4. Ureaplasma spp. were detected more frequently [85\% (95\% CI: $62-100 \%)$ vs. $45 \%(37-52 \%), p=0.006]$ in the recruitment samples of women who delivered preterm compared to those who delivered at term (Table 4). At the species level, the presence of $U$. parvum was significantly increased among PTB cases [77 \% (50-100 \%) vs. $36 \%(29-43 \%), p=0.004]$. There was a small, but significant association between the titre of $U$. parvum and $\mathrm{PTB}$, with an average $U$. parvum titre of $10^{6} \mathrm{CCU}$ in cases of PTB vs. $10^{5} \mathrm{CCU}$ for term cases. U. parvum genotypes SV3 and SV6 were equally represented amongst term pregnancies; however, in women who delivered preterm, genotype SV6 was significantly more common, present in $54 \%(22-85 \%)$ of preterm deliveries compared to $15 \%(10-20 \%)$ of term deliveries $(p=0.002)$. When detected alone, the presence of Candida spp. was not associated with PTB at either the genus or species level. However, when $C$. albicans was detected alongside $U$. parvum a significant positive association with PTB was observed [46 \% (15-78 \%) vs. $13 \%$ (8-18 \%), $p=0.005]$. This association strengthened when $U$. parvum genotype SV6 was present [39 \% (8-69 \%) vs. $7 \%$ (3-11\%), $p=0.003]$.

There was no apparent association between presence of Mycoplasma spp. and PTB; however, M. genitalium was more common in the recruitment samples from women who delivered preterm vs. at term ( 15 vs. $2 \%$, respectively) and this result trended towards significance $(p=0.057)$. Similarly, Candida spp. were also more common in the recruitment samples from women who delivered preterm vs. at term ( 54 vs. $36 \%$, respectively); however, this difference was not statistically significant $(p=0.241)$.

No association was detected between РTB and the presence of either $U$. urealyticum, C. albicans, C. glabrata, non-albicans/glabrata Candida spp. or M. hominis.

Table 3 Association between pharmaceutical/lifestyle characteristics and detection of Ureaplasma, Candida, and Mycoplasma spp. at recruitment $(n=189)^{\mathrm{a}}$

\begin{tabular}{|c|c|c|c|c|c|c|c|c|c|}
\hline \multirow[t]{2}{*}{ Question } & \multicolumn{2}{|c|}{ Ureaplasma spp. } & \multirow[t]{2}{*}{$p$-value } & \multicolumn{2}{|c|}{ Candida spp. } & \multirow[t]{2}{*}{$p$-value } & \multicolumn{2}{|c|}{ Mycoplasma spp. } & \multirow[t]{2}{*}{$p$-value } \\
\hline & $\begin{array}{l}\text { Yes } \\
(n=89)\end{array}$ & $\begin{array}{l}\text { No } \\
(n=100)\end{array}$ & & $\begin{array}{l}\text { Yes } \\
(n=73)\end{array}$ & $\begin{array}{l}\text { No } \\
(n=116)\end{array}$ & & $\begin{array}{l}\text { Yes } \\
(n=25)\end{array}$ & $\begin{array}{l}\text { No } \\
(n=164)\end{array}$ & \\
\hline $\begin{array}{l}\text { Current antibiotic, antifungal or } \\
\text { probiotic use? }\end{array}$ & $1(1 \%)$ & 7 (7 \%) & 0.045 & $3(4 \%)$ & $5(4 \%)$ & 0.947 & $1(4 \%)$ & $7(4 \%)$ & 1.000 \\
\hline Ever diagnosed with a UTI? & $32(36 \%)$ & $43(43 \%)$ & 0.296 & $30(41 \%)$ & $45(39 \%)$ & 0.789 & $8(32 \%)$ & $67(41 \%)$ & 0.387 \\
\hline Ever diagnosed with thrush? & $40(46 \%)$ & $51(51 \%)$ & 0.448 & $34(47 \%)$ & $57(49 \%)$ & 0.798 & $10(42 \%)$ & $81(49 \%)$ & 0.479 \\
\hline Current smoker? & $13(15 \%)$ & $8(8 \%)$ & 0.149 & $13(18 \%)$ & $8(7 \%)$ & 0.020 & $5(20 \%)$ & $16(10 \%)$ & 0.165 \\
\hline Previous smoker? & $33(37 \%)$ & 17 (17\%) & 0.002 & $22(31 \%)$ & $28(24 \%)$ & 0.351 & $11(44 \%)$ & $39(24 \%)$ & 0.036 \\
\hline Currently consumes alcohol? & $1(1 \%)$ & 3 (3 \%) & 0.624 & $2(3 \%)$ & $2(2 \%)$ & 0.642 & $1(4 \%)$ & $3(2 \%)$ & 0.438 \\
\hline Previously consumed alcohol? & $48(54 \%)$ & $60(61 \%)$ & 0.355 & $39(53 \%)$ & $69(60 \%)$ & 0.374 & $14(56 \%)$ & $94(58 \%)$ & 0.875 \\
\hline \multicolumn{10}{|l|}{$\begin{array}{l}\text { Current frequency of sexual } \\
\text { intercourse? }\end{array}$} \\
\hline$<1$ week & $20(23 \%)$ & $22(23 \%)$ & 0.018 & $14(20 \%)$ & $28(24 \%)$ & 0.715 & $3(12 \%)$ & $39(24 \%)$ & 0.001 \\
\hline 1-2 times/week & $38(43 \%)$ & $58(60 \%)$ & & $37(52 \%)$ & $59(51 \%)$ & & $8(32 \%)$ & $88(55 \%)$ & \\
\hline$\geq 3$ times/week & 31 (35\%) & 17 (18 \%) & & $20(28 \%)$ & $28(24 \%)$ & & $14(56 \%)$ & 34 (21\%) & \\
\hline
\end{tabular}

${ }^{a}$ wk week; bold type indicates statistical significance $(p<0.05)$ 
Table 4 Vaginal colonisation rates of Ureaplasma, Candida and Mycoplasma spp. at recruitment in women who delivered spontaneously preterm vs. at term ${ }^{a}$

\begin{tabular}{|c|c|c|c|}
\hline & $\begin{array}{l}\text { Preterm } \\
N=13\end{array}$ & $\begin{array}{l}\text { Term } \\
N=174\end{array}$ & $p$-value \\
\hline Ureaplasma spp. & $11(85 \%)$ & 78 (45 \%) & 0.006 \\
\hline U. parvum & $10(77 \%)$ & $63(36 \%)$ & 0.004 \\
\hline U. urealyticum & $2(15 \%)$ & $23(13 \%)$ & 0.687 \\
\hline Titre (CCU) of U. parvum ${ }^{b}$ & $6(5-6 ; 3-7)$ & $5(4-6 ; 2-8)$ & 0.043 \\
\hline Serovar 3 of U. parvum & $3(23 \%)$ & $23(13 \%)$ & 0.399 \\
\hline Serovar 6 of $U$. parvum & 7 (54 \%) & $26(15 \%)$ & 0.002 \\
\hline Candida spp. & $7(54 \%)$ & $63(36 \%)$ & 0.241 \\
\hline C. albicans & $6(46 \%)$ & $55(32 \%)$ & 0.358 \\
\hline C. glabrata & $1(8 \%)$ & $9(5 \%)$ & 0.522 \\
\hline Non-albicans/non-glabrata & 0 & $4(2 \%)$ & 1.000 \\
\hline \multicolumn{4}{|l|}{ Mycoplasma spp. } \\
\hline M. hominis & $2(15 \%)$ & $19(11 \%)$ & 0.644 \\
\hline M. genitalium & $2(15 \%)$ & $4(2 \%)$ & 0.057 \\
\hline U. parvum + C. albicans & $6(46 \%)$ & $22(13 \%)$ & 0.005 \\
\hline U. parvum serovar $6+C$. albicans & $5(39 \%)$ & 12 (7 \%) & 0.003 \\
\hline
\end{tabular}

${ }^{a}$ Bold type indicates statistical significance $(p<0.05)$

${ }^{\mathrm{b}}$ median, interquartile range, range

\section{Spontaneous preterm birth $<34$ weeks $G A$ and birthweight $<1500 \mathrm{~g}$}

Five babies were born $<34$ weeks GA, including two weighing $<1500 \mathrm{~g}$ (Table 5). U. parvum was detected at recruitment in all cases and in $80 \%(4 / 5)$ of these, genotype SV6 was present. In the four earliest preterm deliveries (25.9-31.4 weeks GA), both $U$. parvum and $C$. albicans were detected at recruitment (Table 5). Unfortunately, due to insufficient numbers, no statistical analyses were able to be performed on risk of PTB $<34$ weeks GA.

\section{Discussion}

Numerous previous studies have described an association between detection of Ureaplasma spp. in the vagina during pregnancy and subsequent PTB [1]. Consistent with data from the majority of these studies, our findings confirm a significant association between vaginal colonisation by Ureaplasma spp. and PTB risk.
However, unlike the vast majority of previous research, we have further discriminated between human Ureaplasmas at the species level. Our finding that vaginal colonisation by $U$. parvum, but not $U$. urealyticum, was associated with an increased risk of PTB, compared to colonisation by Ureaplasma spp. in general, highlights a major limitation in these previous studies. This is despite the fact that in $1990 U$. urealyticum was classified as two distinct biovars, parvo ( $U$. parvum) and T960 (U. urealyticum) [27], and then formally proposed as two separate species in 2002 [28]. In addition, species (biovar)-level PCR detection assays have been available since 1993 [29]; hence, the ability to study this organism at the species level has existed for many years. It is important that future studies ensure that species-level analyses are carried out, especially those examining pregnancy outcome, as our data showed that $U$. parvum confers the greatest risk of PTB. This is in stark contrast to other disease phenotypes, such as pelvic inflammatory disease [8], endometritis [8], nongonococcal urethritis $[8-10,12]$ and post-gonococcal urethritis [11], where $U$. urealyticum has been reported to be significantly associated with disease, but not $U$. parvum. In previous studies [30-45] that examined the obstetric consequences of vaginal colonisation by Ureaplasma spp., where there were defined case and control groups, only three discriminated between $U$. parvum and $U$. urealyticum. Similar to our study, the two most recent of these, Mitsunari et al. [32] and Kataoka et al. [42] reported that vaginal colonisation by $U$. parvum, but not $U$. urealyticum, was significantly associated with PTB. However, in contrast, a study from the late 1990s by Abele-Horn et al. [34] came to the opposite conclusion, with $U$. urealyticum apparently having more adverse effects on birth weight, gestational age and preterm delivery compared to $U$. parvum. These are the only authors, to our knowledge, that have reported an association between $U$. urealyticum and PTB; however, they employed a unique set of inclusion criteria whereby women were recruited who were solely colonised with Ureaplasma spp. and no other 'abnormal' microorganisms, including C. albicans, Gardnerella vaginalis and many others. This may have introduced confounders.

Table 5 Detection of organisms at recruitment and birth characteristics for babies born spontaneously at $<34$ weeks $G A(n=5)^{a}$

\begin{tabular}{|c|c|c|c|c|c|c|c|c|c|}
\hline GA (wk) & BW (g) & Sex & U. parvum & Titre $\left(C C U-10^{\wedge}\right)$ & U. parvum/U. urealyticum & U. parvum SV6 & C. albicans & M. hominis & M. genitalium \\
\hline 25.9 & 690 & M & $\checkmark$ & 6 & U. parvum & $\checkmark$ & $\checkmark$ & $\checkmark$ & $\checkmark$ \\
\hline 28.0 & 760 & M & $\checkmark$ & 7 & U. parvum & $\checkmark$ & $\checkmark$ & - & - \\
\hline 30.9 & 1560 & M & $\checkmark$ & 6 & U. parvum & - & $\checkmark$ & $\checkmark$ & - \\
\hline 31.4 & 1950 & M & $\checkmark$ & 5 & Both & $\checkmark$ & $\checkmark$ & - & $\checkmark$ \\
\hline 32.0 & 1820 & $\mathrm{~F}$ & $\checkmark$ & 6 & U. parvum & $\checkmark$ & - & - & - \\
\hline
\end{tabular}

${ }^{a} w k$ weeks, $g$ grams, CCU colour changing units; a tick $(\checkmark)$ represents presence of organism, a dash (-) absence of organism 
We have previously discussed the history and limitations associated with serotyping/genotyping of $U$. parvum and $U$. urealyticum [23]. As a result of this, we developed a HRM PCR assay capable of detecting the four genotypes of $U$. parvum directly from clinical samples and suggested that this assay may provide valuable information relating to $U$. parvum genotype status and specific clinical conditions [23]. In the current study, using this assay, we were able to identify single $U$. parvum genotypes from $91 \%$ of colonised samples, with a further $3 \%$ resolved to the level of 'mixed' genotypes. From 74 U. parvum positive samples, we identified genotypes SV6 (42 \%) and SV3 (36 \%) as the most common, followed by SV1 (15\%). This genotype distribution is slightly different to that described by Xiao et al. [8], who reported that in 169 vaginal samples from healthy pregnant women, SV3 (63 \%) was the most common, followed by SV6 (30 \%), SV1 (24 \%) and SV14 (4\%). This may indicate that the geographical location of the cohort influences serovar prevalence. Unfortunately, these authors did not provide any data on potential associations between genotype and adverse pregnancy outcome. However, in another sample set from the same study, Xiao et al. [8] reported a significant association between detection of $U$. parvum genotype SV6 in placental tissue and histologic chorioamnionitis, a condition that is indicative of infection-associated PTB. This corroborates our finding of a significant association between detection of $U$. parvum genotype SV6 in the vagina and $\mathrm{PTB}<37$ weeks $\mathrm{GA}$, in addition to our detection of this genotype in $4 / 6$ cases of PTB $<34$ weeks GA.

To our knowledge, the only other study that has examined $U$. parvum genotypes present in vaginal samples is that of De Francesco et al. [46], who collected cervical, urethral, and vaginal swabs from 806 women. In contrast to our results, these authors reported that genotypes SV3 and SV14 (not separated beyond this level) and SV1 were the most common detected, representing 39 and $37 \%$ of the 158 women who were positive for Ureaplasma spp. Genotype SV6 was detected in $24 \%$ of cases and was apparently associated with a vaginal microbiota deemed 'normal', compared to that associated with SV3/SV14, which was linked to an absence of lactobacilli. However, it is difficult to compare these results to those from our study, as De Francesco et al. [46] did not differentiate the patient type associated with positive samples, instead compiling women from outpatients for gynaecological health care control, routine screening for pregnancy, infertility problems and those with symptoms of genital infections into one group. As such, the multiple phenotypes present make it impossible to extrapolate phenotype-specific data from this study.

Another study that examined $U$. parvum genotype distribution was by Sung et al. [47] and involved preterm neonates with bronchopulmonary dysplasia (BPD). It reported that SV3 and SV6, either alone or together, accounted for $96 \%$ of $U$. parvum isolates detected in endotracheal and/or nasopharyngeal aspirates. However, these authors failed to find an association between genotype and the development of moderate to severe BPD.

Also of interest, and particularly relevant to the clinical use of our HRM assay, we noted that $U$. parvum genotype colonisation in our study was typically singular and in nearly all cases was stable throughout pregnancy. Although we are unable to compare this to the work of any previous studies due to omission of details relating to single/multiple genotype detection [46] or presenting multiple genotype data including $U$. urealyticum genotypes $[8,47]$, it is interesting to note that studies that have looked at $U$. urealyticum genotype distribution generally report that when detected, multiple genotypes are typically present $[8,47,48]$. However, this may also be a result of problems with cross-reactivity associated with PCR assays for these genotypes [8].

We did not detect a significant association between the presence of vaginal Candida spp. alone and PTB, a result that contradicts four previous studies [4-7] and a recent systematic review [49], although we did observe a trend towards significance. This warrants further investigation in a larger cohort of women. However, when vaginal colonisation by $U$. parvum was accompanied by $C$. albicans (the most commonly detected Candida spp. in our study), the odds ratio (OR) for risk of PTB increased marginally from 3.32 (U. parvum alone) to 3.77 (both organisms). Stratifying $U$. parvum by genotype, additional increases in risk were seen when $C$. albicans was combined with $U$. parvum genotype SV6, with the OR rising from 4.17 to 5.16 . Both organisms have previously been associated with increased PTB risk $[1,5,50]$, while colonisation of amniotic fluid by $C$. albicans has been linked to severe fetal injury [51-53]; however, no previous studies have looked at the effects of combined asymptomatic vaginal colonisation and pregnancy outcome, particularly regarding $U$. parvum genotype. Further research is warranted, firstly to confirm our novel findings in a larger cohort, and second to attempt to uncover what factors may be responsible for this association. If our findings are confirmed, then detection of these two organisms during the early second trimester of pregnancy could prove to be a useful indicator of women at a high risk of infection-associated PTB and therefore targets for antimicrobial therapy.

Although we have discussed the results of our study in terms of presence/absence of specific bacteria at $\sim 21$ weeks GA (primarily as this is of major relevance to allow implementation of suitable treatment regimens for prevention of PTB), our study also examined vaginal samples at two additional time points $(\sim 28$ weeks and 
$\sim 36$ weeks GA). To the best of our knowledge, this is the first study to examine the dynamics of Ureaplasma spp., Mycoplasma spp. and Candida spp. throughout the second and third trimesters of pregnancy. We demonstrated that detection of all organisms (with the exception of C. glabrata) was very stable throughout the three sampling points, particularly so for M. genitalium and $U$. parvum. In addition, for $U$. parvum we also demonstrated that in nearly all cases, the genotype detected at recruitment was maintained throughout the second and third time points. These are very important findings as they demonstrate that detection of these organisms early in the second trimester of pregnancy is highly predictive of their presence both early and late in the third trimester, and provides valuable information for future diagnostic assays aiming to predict women at risk of PTB.

Of significant relevance to use of $U$. parvum detection assays in future clinical diagnostic applications, we showed near $100 \%$ concordance between detection of Ureaplasma spp. in clinical samples using either culture-based or PCR methods, in contrast to some previous authors who reported disparities between the two techniques [54-56]. It has been well established that Ureaplasma sp. cells are fragile and in order to optimise recovery from clinical samples, special attention needs to be paid to sample collection, storage and transportation, in addition to the media used for culture [57]. Our results are most likely a reflection of our highly stringent sample collection and culture conditions, whereby swabs were immediately placed into UTM media, stored at $4^{\circ}$ $\mathrm{C}$ and cultured in 10B broth within $24 \mathrm{~h}$ of collection under microaerophilic conditions. This is important, as despite the increased use of molecular methods for detection of Ureaplasma spp., culture is likely to play a key role alongside these in future studies attempting to document virulence traits of strains associated with specific disease phenotypes.

In addition to culturing Ureaplasma spp. from our clinical samples, we also documented the titre of organisms present in each. We identified a small, but significant association between the titre of $U$. parvum and PTB, with an average $U$. parvum titre of $10^{6} \mathrm{CCU}$ in cases of PTB vs. $10^{5} \mathrm{CCU}$ for term cases. Although this may appear significant statistically, it is unlikely to be clinically relevant. We used eight 10 -fold serial dilutions of 10B broth culture for quantitation and expressed our titres in colour changing units $(\mathrm{CCU})$, a technique that has been widely used in Ureaplasma sp. culture [58-61]. A limitation of the CCU method is that although it is far more suited to quantitation of large sample numbers, it really is semi-quantitative in that the titre values obtained actually represent a range rather than hard values. For instance, $10^{6} \mathrm{CCU}$ may actually be $1,000,000-9,000,000$ cells. As a result, we believe clinical significance would have only been justified in the case of a difference of two dilution series, as opposed to a single series, such as we observed. Standard solid agar plate quantitation methods are not well suited to Ureaplasma spp. due to the tiny colony size and associated quantitation difficulties (a microscope with $\sim 10-40 \times$ magnification is required). Despite this, Abele-Horn et al. [35] used this method for quantitation and following multivariate analysis of 172 Ureaplasma-colonised and 123 non-colonised pregnant women, they reported that Ureaplasma sp. vaginal colonisation was an independent risk factor for PTB at $10^{5} \mathrm{CFU} / \mathrm{mL}$ and for chorioamnionitis at both $10^{4}-10^{5}$ and $10^{5} \mathrm{CFU} / \mathrm{mL}$. Lower colonisation levels had no adverse effects on pregnancy outcome [35]. Regardless of the method used though, it could be argued that accurate quantitation of any bacteria from a swab-collected sample is confounded by the manner of sample collection, which is likely to have a large effect on the results.

Although our sample size was too small to accurately document any association between detection of vaginal M. genitalium and PTB, we observed a trend towards significance, with detection rates of 12 and $2 \%$ at recruitment in women delivering preterm and term, respectively. This result is particularly interesting in that it conflicts with the findings of four previous studies, all of which found no association between vaginal M. genitalium and PTB; interestingly, they reported detection rates $(0.7-8 \%)$ somewhat lower than those reported here [62-65]. One of these was by Labbe et al. [65] who reported rates of $8 \%$ in preterm deliveries $(16 / 183)$ and $6 \%$ in women delivering at term $(36 / 564)$ in a population of women from a developing country, many of whom also screened positive for other known sexually transmitted infections, including human immunodeficiency virus (HIV). In comparison, Hitti et al. [66], reported detection rates of only $4 \%(29 / 661)$ and $2 \%(12 /$ 667) in Peruvian women who delivered preterm and term, respectively. This finding was significant, accompanied by an odds ratio of 2.5 (95\% CI: 1.2-5.0). Of particular interest, both Oakeshott et al. [63] and Hitti et al. [66] documented that vaginal M. genitalium was more commonly observed in women of a younger maternal age $(<20$ years and mean 21.2 years, respectively). This was also true in our cohort, where the mean age of women in which vaginal $M$. genitalium colonisation was detected was 24.3 years (in comparison to the overall cohort mean age of 30), and perhaps suggests that maternal age needs to be taken into account when assessing microbiological-associated PTB risk.

Many previous studies that have examined associations between vaginal bacterial colonisation and PTB have not considered the effect of lifestyle factors on the species 
present. By administering questionnaires to our participants at each sampling point (asking about such lifestyle factors as smoking before/during pregnancy and the amount of sexual intercourse during pregnancy), we sought to establish if there was a relationship between these factors and organism presence. For both Ureaplasma spp. and Mycoplasma spp., we observed significantly higher detection rates in women who reported having sexual intercourse greater than or equal to 3 times per week during the course of their pregnancy. Considering that both of these organisms are known colonisers of both the female and male genital tracts [67], and are also considered sexually-transmitted infections in certain circumstances [20], this result is not surprising. However, of particular interest, we also observed associations between women who either smoked prior to or during their pregnancy and increased detection rates of Ureaplasma, Mycoplasma and/or Candida spp. Of statistical significance, higher detection rates of Ureaplasma spp. (37 vs. $17 \%$ ) and Mycoplasma spp. (44 vs. $24 \%)$ were observed in women who smoked prior to their pregnancy and for Candida spp., colonisation rates were significantly higher in women who continued to smoke throughout their pregnancy (18 vs. $7 \%$ ). A similar phenomenon has been reported previously in relation to smoking and vaginal microbiology in the case of human papillomavirus (HPV) infection [68] and also for bacterial vaginosis [15]. Although the association between BV and smoking may help to explain the association between Ureaplasma spp. and Mycoplasma spp., both of which have been previously reported as BVassociated agents [3], Candida spp. are not typically associated with BV. In addition, whereas it has been reported that the anti-estrogenic effect of smoking [69] may predispose a woman to BV [16], it has been previously documented that Candida spp. are more prevalent during pregnancy as a result of the increased amounts of estrogen present [70]. One possible explanation could be that benzo[a]pyrene, found in trace amounts in the vaginal secretions of smokers, has been shown to significantly induce Lactobacillus spp. prophages [71]. This would result in a decrease in numbers of vaginal Lactobacillus spp. due to cell lysis from lytic phages, potentially providing a more favourable environment for Candida spp. and especially BV-associated organisms, as Lactobacillus spp. are critical for maintenance of an acidic vaginal $\mathrm{pH}$ [72]. Detailed metagenomics studies would be required to address this hypothesis.

\section{Conclusions}

Although many previous studies have shown associations between Ureaplasma spp. and PTB, our study has demonstrated the importance of detecting $U$. parvum and $U$. urealyticum as individual species, and for $U$. parvum, genotype, when investigating the relationship between vaginal colonisation and PTB risk. We found that vaginal $U$. parvum colonisation was associated with increased risk of spontaneous PTB, and that detection of $U$. parvum genotype SV6 was of even higher significance, especially when combined with the presence of $C$. albicans. This result now needs to be confirmed in a larger cohort of women, preferably in both similar and different ethnic populations, in order to evaluate its use as an early detection biomarker for risk of PTB. Our finding that colonisation status is preserved across pregnancy is clinically important, suggesting that for Ureaplasma, Mycoplasma and Candida spp., a single sample taken in pregnancy has diagnostic and prognostic utility. The cause and effect relationships between colonisation with $U$. parvum genotype SV6, C. albicans and preterm labour, however, are unproven. Further work is currently underway to attempt to identify potential virulence factors at the genome level, in addition to describing the relationship between vaginal colonisation and intraamniotic infection with specific organisms in order to illuminate a plausible mechanism. Lastly, our finding that smoking either prior to pregnancy or during pregnancy is significantly associated with Ureaplasma, Mycoplasma and Candida spp. vaginal colonisation status offers additional insight into relationships between lifestyle and pregnancy risk. Larger studies are needed to confirm these findings in cohorts of past and current smokers.

\section{Acknowledgements}

Funding for this study was provided by the Women and Infants Research Foundation (WIRF) of Western Australia and Channel 7 Telethon Trust. MSP is supported by a National Health and Medical Research Council Project Grant (APP1077931). LLF was supported by a Bachelor of Medical Science

(Honours) scholarship from WIRF. We would also like to acknowledge the hard work of the research midwives involved in this study, Mrs Anne-Marie Shortt (RM) and Mrs Suzie Allen (RM), as well as the 206 women who participated.

\section{Authors' contributions}

MSP Conceived and designed the study, conducted laboratory analyses, analysed the data, and wrote the manuscript. DJ Contributed to study design, conducted laboratory analyses, and reviewed the manuscript. RW Conducted laboratory analyses and reviewed the manuscript. LLF Conducted laboratory analyses and reviewed the manuscript. EAN Analysed the data, conducted all statistical analyses, and reviewed the manuscript. MWK Conducted laboratory analyses and reviewed the manuscript. JAK

Contributed to study design, and reviewed the manuscript. JPN Contributed to study design, and reviewed the manuscript. All authors read and approved the final manuscript.

\section{Competing interests}

The authors declare that they have no competing interests.

\section{Author details}

'School of Women's and Infants' Health, University of Western Australia, 2nd Floor, Block A, King Edward Memorial Hospital, Subiaco, WA 6008, Australia.

${ }^{2}$ Women and Infants Research Foundation, Biostatistics and Research Design Unit, Subiaco, WA 6008, Australia.

Received: 5 November 2015 Accepted: 11 October 2016

Published online: 18 October 2016 


\section{References}

1. Capoccia R, Greub G, Baud D. Ureaplasma urealyticum, Mycoplasma hominis and adverse pregnancy outcomes. Curr Opin Infect Dis. 2013;26(3):231-40.

2. McGowin CL, Anderson-Smits C. Mycoplasma genitalium: an emerging cause of sexually transmitted disease in women. PLoS Pathog. 2011;7(5):e1001324.

3. Malaguti N, Bahls LD, Uchimura NS, Gimenes F, Consolaro ME. Sensitive Detection of Thirteen Bacterial Vaginosis-Associated Agents Using Multiplex Polymerase Chain Reaction. Biomed Res Int. 2015;2015:645853.

4. Kiss $H$, Petricevic L, Martina S, Husslein P. Reducing the rate of preterm birth through a simple antenatal screen-and-treat programme: a retrospective cohort study. Eur J Obstet Gynecol Reprod Biol. 2010;153(1):38-42.

5. Czeizel AE, Fladung B, Vargha P. Preterm birth reduction after clotrimazole treatment during pregnancy. Eur J Obstet Gynecol Reprod Biol. 2004;116(2):157-63.

6. Czeizel AE, Rockenbauer M. A lower rate of preterm birth after clotrimazole therapy during pregnancy. Paediatr Perinat Epidemiol. 1999;13(1):58-64.

7. Roberts CL, Rickard K, Kotsiou G, Morris JM. Treatment of asymptomatic vaginal candidiasis in pregnancy to prevent preterm birth: an open-label pilot randomized controlled trial. BMC Pregnancy Childbirth. 2011;11:18.

8. Xiao L, Paralanov V, Glass Jl, Duffy LB, Robertson JA, Cassell GH, Chen Y, Waites KB. Extensive horizontal gene transfer in ureaplasmas from humans questions the utility of serotyping for diagnostic purposes. J Clin Microbiol. 2011:49(8):2818-26.

9. Deguchi T, Yoshida T, Miyazawa T, Yasuda M, Tamaki M, Ishiko H, Maeda S. Association of Ureaplasma urealyticum (biovar 2) with nongonococcal urethritis. Sex Transm Dis. 2004;31(3):192-5.

10. Maeda S, Deguchi T, Ishiko H, Matsumoto T, Naito S, Kumon H, Tsukamoto T, Onodera S, Kamidono S. Detection of Mycoplasma genitalium, Mycoplasma hominis, Ureaplasma parvum (biovar 1) and Ureaplasma urealyticum (biovar 2) in patients with non-gonococcal urethritis using polymerase chain reactionmicrotiter plate hybridization. Int J Urol. 2004;11(9):750-4.

11. Yokoi S, Maeda S, Kubota Y, Tamaki M, Mizutani K, Yasuda M, Ito S, Nakano M, Ehara H, Deguchi T. The role of Mycoplasma genitalium and Ureaplasma urealyticum biovar 2 in postgonococcal urethritis. Clin Infect Dis. 2007:45(7):866-71.

12. Povlsen $K$, Bjornelius $E$, Lidbrink $P$, Lind I. Relationship of Ureaplasma urealyticum biovar 2 to nongonococcal urethritis. Eur J Clin Microbiol Infect Dis. 2002;21(2):97-101.

13. Blencowe $H$, Cousens $S$, Oestergaard MZ, Chou D, Moller AB, Narwal R, Adler A, Vera Garcia C, Rohde S, Say L, et al. National, regional, and worldwide estimates of preterm birth rates in the year 2010 with time trends since 1990 for selected countries: a systematic analysis and implications. Lancet. 2012;379(9832):2162-72.

14. Goldenberg RL, Culhane JF, lams JD, Romero R. Epidemiology and causes of preterm birth. Lancet. 2008;371(9606):75-84

15. Bagaitkar J, Demuth DR, Scott DA. Tobacco use increases susceptibility to bacterial infection. Tob Induc Dis. 2008;4:12

16. Brotman RM, He X, Gajer P, Fadrosh D, Sharma E, Mongodin EF, Ravel J, Glover ED, Rath JM. Association between cigarette smoking and the vaginal microbiota: a pilot study. BMC Infect Dis. 2014;14:471.

17. Larsson PG, Fahraeus L, Carlsson B, Jakobsson T, Forsum U. Predisposing factors for bacterial vaginosis, treatment efficacy and pregnancy outcome among term deliveries; results from a preterm delivery study. BMC Womens Health. 2007;7:20.

18. Evans AL, Scally AJ, Wellard SJ, Wilson JD. Prevalence of bacterial vaginosis in lesbians and heterosexual women in a community setting. Sex Transm Infect. 2007:83(6):470-5.

19. Nelson DB, Bellamy S, Odibo A, Nachamkin I, Ness RB, Allen-Taylor L. Vaginal symptoms and bacterial vaginosis (BV): how useful is self-report? Development of a screening tool for predicting BV status. Epidemiol Infect. 2007;135(8):1369-75

20. Moi H, Blee K, Horner PJ. Management of non-gonococcal urethritis. BMC Infect Dis. 2015;15(1):294

21. Ravel J, Gajer P, Abdo Z, Schneider GM, Koenig SS, McCulle SL, Karlebach S, Gorle R, Russell J, Tacket CO, et al. Vaginal microbiome of reproductive-age women. Proc Natl Acad Sci U S A. 2011;108 Suppl 1:4680-7.

22. Yi J, Yoon BH, Kim EC. Detection and biovar discrimination of Ureaplasma urealyticum by real-time PCR. Mol Cell Probes. 2005;19(4):255-60.

23. Payne MS, Tabone T, Kemp MW, Keelan JA, Spiller OB, Newnham JP. Highresolution melt PCR analysis for the genotyping of Ureaplasma parvum directly from clinical samples. J Clin Microbiol. 2013;52(2):599-606.
24. Ferandon C, Peuchant O, Janis C, Benard A, Renaudin H, Pereyre S, Bebear $C$. Development of a real-time PCR targeting the yidC gene for the detection of Mycoplasma hominis and comparison with quantitative culture. Clin Microbiol Infect. 2011;17(2):155-9.

25. Jensen JS, Bjornelius E, Dohn B, Lidbrink P. Use of TaqMan 5' nuclease real-time PCR for quantitative detection of Mycoplasma genitalium DNA in males with and without urethritis who were attendees at a sexually transmitted disease clinic. J Clin Microbiol. 2004;42(2):683-92.

26. Innings A, Ullberg M, Johansson A, Rubin CJ, Noreus N, Isaksson M, Herrmann B. Multiplex real-time PCR targeting the RNase P RNA gene for detection and identification of Candida species in blood. J Clin Microbiol. 2007;45(3):874-80

27. Robertson JA, Pyle LE, Stemke GW, Finch LR. Human ureaplasmas show diverse genome sizes by pulsed-field electrophoresis. Nucleic Acids Res. 1990;18(6):1451-5.

28. Robertson JA, Stemke GW, Davis Jr JW, Harasawa R, Thirkell D, Kong F, Shepard MC, Ford DK. Proposal of Ureaplasma parvum sp. nov. and emended description of Ureaplasma urealyticum (Shepard et al. 1974) Robertson et al. 2001. Int J Syst Evol Microbiol. 2002;52(Pt 2):587-97.

29. Robertson JA, Vekris A, Bebear C, Stemke GW. Polymerase chain reaction using 165 rRNA gene sequences distinguishes the two biovars of Ureaplasma urealyticum. J Clin Microbiol. 1993;31(4):824-30.

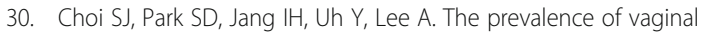
microorganisms in pregnant women with preterm labor and preterm birth. Ann Lab Med. 2012;32(3):194-200.

31. Breugelmans M, Vancutsem E, Naessens A, Laubach M, Foulon W. Association of abnormal vaginal flora and Ureaplasma species as risk factors for preterm birth: a cohort study. Acta Obstet Gynecol Scand. 2010;89(2): 256-60.

32. Mitsunari M, Yoshida S, Deura I, Horie S, Tsukihara S, Harada T, Irie T, Terakawa N. Cervical Ureaplasma urealyticum colonization might be associated with increased incidence of preterm delivery in pregnant women without prophlogistic microorganisms on routine examination. J Obstet Gynaecol Res. 2005;31(1):16-21.

33. Harada K, Tanaka H, Komori S, Tsuji Y, Nagata K, Tsutsui H, Koyama K. Vaginal infection with Ureaplasma urealyticum accounts for preterm delivery via induction of inflammatory responses. Microbiol Immunol. 2008;52(6):297-304

34. Abele-Horn M, Wolff C, Dressel P, Pfaff F, Zimmermann A. Association of Ureaplasma urealyticum biovars with clinical outcome for neonates, obstetric patients, and gynecological patients with pelvic inflammatory disease. J Clin Microbiol. 1997;35(5):1199-202.

35. Abele-Horn M, Scholz M, Wolff C, Kolben M. High-density vaginal Ureaplasma urealyticum colonization as a risk factor for chorioamnionitis and preterm delivery. Acta Obstet Gynecol Scand. 2000;79(11):973-8.

36. Carey JC, Blackwelder WC, Nugent RP, Matteson MA, Rao AV, Eschenbach DA, Lee ML, Rettig PJ, Regan JA, Geromanos KL. Antepartum cultures for Ureaplasma urealyticum are not useful in predicting pregnancy outcome. The Vaginal Infections and Prematurity Study Group. Am J Obstet Gynecol. 1991;164(3):728-33.

37. Horowitz S, Horowitz J, Mazor M, Porath A, Glezerman M. Ureaplasma urealyticum cervical colonization as a marker for pregnancy complications. Int J Gynaecol Obstet. 1995:48(1):15-9.

38. Kafetzis DA, Skevaki CL, Skouteri V, Gavrili S, Peppa K, Kostalos C, Petrochilou $\checkmark$, Michalas S. Maternal genital colonization with Ureaplasma urealyticum promotes preterm delivery: association of the respiratory colonization of premature infants with chronic lung disease and increased mortality. Clin Infect Dis. 2004;39(8):1113-22.

39. Kacerovsky M, Pavlovsky M, Tosner J. Preterm premature rupture of the membranes and genital mycoplasmas. Acta Med (Hradec Kralove). 2009;52(3):117-20

40. Rezeberga D, Lazdane G, Kroica J, Sokolova L, Donders GG. Placental histological inflammation and reproductive tract infections in a low risk pregnant population in Latvia. Acta Obstet Gynecol Scand. 2008;87(3):360-5.

41. Horowitz S, Mazor M, Horowitz J, Porath A, Glezerman M. Antibodies to Ureaplasma urealyticum in women with intraamniotic infection and adverse pregnancy outcome. Acta Obstet Gynecol Scand. 1995;74(2):132-6.

42. Kataoka S, Yamada T, Chou K, Nishida R, Morikawa M, Minami M, Yamada H, Sakuragi N, Minakami H. Association between preterm birth and vaginal colonization by mycoplasmas in early pregnancy. J Clin Microbiol. 2006:44(1):51-5. 
43. Govender S, Theron GB, Odendaal HJ, Chalkley LJ. Prevalence of genital mycoplasmas, ureaplasmas and chlamydia in pregnancy. J Obstet Gynaecol. 2009;29(8):698-701.

44. Lamont RF, Taylor-Robinson D, Wigglesworth JS, Furr PM, Evans RT, Elder MG. The role of mycoplasmas, ureaplasmas and chlamydiae in the genital tract of women presenting in spontaneous early preterm labour. J Med Microbiol. 1987;24(3):253-7.

45. Abele-Horn M, Peters J, Genzel-Boroviczeny O, Wolff C, Zimmermann A, Gottschling W. Vaginal Ureaplasma urealyticum colonization: influence on pregnancy outcome and neonatal morbidity. Infection. 1997;25(5):286-91.

46. De Francesco MA, Negrini R, Pinsi G, Peroni L, Manca N. Detection of Ureaplasma biovars and polymerase chain reaction-based subtyping of Ureaplasma parvum in women with or without symptoms of genital infections. Eur J Clin Microbiol Infect Dis. 2009;28(6):641-6.

47. Sung TJ, Xiao L, Duffy L, Waites KB, Chesko KL, Viscardi RM. Frequency of ureaplasma serovars in respiratory secretions of preterm infants at risk for bronchopulmonary dysplasia. Pediatr Infect Dis J. 2011;30(5):379-83.

48. Eun HS, Lee SM, Park MS, Park KI, Namgung R, Lee C. Serological investigation of Ureaplasma urealyticum in Korean preterm infants. Korean J Pediatr. 2013;56(11):477-81

49. Roberts $\mathrm{CL}$, Algert $\mathrm{CS}$, Rickard KL, Morris JM. Treatment of vaginal candidiasis for the prevention of preterm birth: a systematic review and meta-analysis. Syst Rev. 2015;4:31

50. Payne MS, Bayatibojakhi S. Exploring preterm birth as a polymicrobial disease: an overview of the uterine microbiome. Front Immunol. 2014;5:595

51. Maneenil G, Payne MS, Senthamarai Kannan P, Kallapur SG, Kramer BW, Newnham JP, Miura Y, Jobe AH, Kemp MW. Fluconazole treatment of intrauterine Candida albicans infection in fetal sheep. Pediatr Res. 2015;77(6):740-8

52. Payne MS, Kemp MW, Kallapur SG, Kannan PS, Saito M, Miura Y, Newnham JP Stock S, Ireland DJ, Kramer BW, et al. Intrauterine Candida albicans infection elicits severe inflammation in fetal sheep. Pediatr Res. 2014;75(6):716-22.

53. Bean LM, Jackson JR, Dobak WJ, Beiswenger TR, Thorp JA. Intra-amniotic fluconazole therapy for Candida albicans intra-amniotic infection. Obstet Gynecol. 2013;121(2 Pt 2 Suppl 1):452-4.

54. Petrikkos GL, Hadjisoteriou M, Daikos GL. PCR versus culture in the detection of vaginal Ureaplasma urealyticum and Mycoplasma hominis. Int J Gynaecol Obstet. 2007:97(3):202-3.

55. Teng K, Li M, Yu W, Li H, Shen D, Liu D. Comparison of PCR with culture for detection of Ureaplasma urealyticum in clinical samples from patients with urogenital infections. J Clin Microbiol. 1994;32(9):2232-4.

56. Romero R, Miranda J, Kusanovic JP, Chaiworapongsa T, Chaemsaithong P, Martinez A, Gotsch F, Dong Z, Ahmed Al, Shaman M, et al. Clinical chorioamnionitis at term I: microbiology of the amniotic cavity using cultivation and molecular techniques. J Perinat Med. 2015;43(1):19-36.

57. Furr PM. Cultivation of Ureaplasmas. In: Miles RJ, Nicholas RAJ, editors. Methods in Molecular Biology: Mycoplasma Protocols, vol. 104. Totowa: Humana Press Inc; 1998. p. 53-9.

58. Kemp MW, Miura Y, Payne MS, Watts R, Megharaj S, Jobe AH, Kallapur SG, Saito M, Spiller OB, Keelan JA, et al. Repeated maternal intramuscular or intraamniotic erythromycin incompletely resolves intrauterine Ureaplasma parvum infection in a sheep model of pregnancy. Am J Obstet Gynecol. 2014;211(2):134 e131-139.

59. Miura Y, Payne MS, Keelan JA, Noe A, Carter S, Watts R, Spiller OB, Jobe AH, Kallapur SG, Saito M, et al. Maternal intravenous treatment with either azithromycin or solithromycin clears Ureaplasma parvum from the amniotic fluid in an ovine model of intrauterine infection. Antimicrob Agents Chemother. 2014;58(9):5413-20.

60. Beeton ML, Chalker VJ, Maxwell NC, Kotecha S, Spiller OB. Concurrent titration and determination of antibiotic resistance in ureaplasma species with identification of novel point mutations in genes associated with resistance. Antimicrob Agents Chemother. 2009;53(5):2020-7.

61. Jalil N, Gilchrist C, Taylor-Robinson D. Factors influencing the in-vitro sensitivity of Ureaplasma urealyticum to tetracyclines. J Antimicrob Chemother. 1989;23(3):341-5

62. Kovachev E, Popova A, Protopopov F, Minkov R, Tsvetkova S. Association between Mycoplasma genitalium and preterm labor. Akush Ginekol. 2002;41(6):26-9.

63. Oakeshott P, Hay P, Taylor-Robinson D, Hay S, Dohn B, Kerry S, Jensen JS. Prevalence of Mycoplasma genitalium in early pregnancy and relationship between its presence and pregnancy outcome. BJOG. 2004;111(12):1464-7.
64. Lu GC, Schwebke JR, Duffy LB, Cassell GH, Hauth JC, Andrews WW, Goldenberg RL. Midtrimester vaginal Mycoplasma genitalium in women with subsequent spontaneous preterm birth. Am J Obstet Gynecol. 2001;185(1):163-5.

65. Labbe AC, Frost E, Deslandes S, Mendonca AP, Alves AC, Pepin J. Mycoplasma genitalium is not associated with adverse outcomes of pregnancy in Guinea-Bissau. Sex Transm Infect. 2002;78(4):289-91.

66. Hitti J, Garcia P, Totten P, Paul K, Astete S, Holmes KK. Correlates of cervical Mycoplasma genitalium and risk of preterm birth among Peruvian women. Sex Transm Dis. 2010;37(2):81-5.

67. Waites KB, Katz B, Schelonka RL. Mycoplasmas and ureaplasmas as neonatal pathogens. Clin Microbiol Rev. 2005;18(4):757-89.

68. da Silva CS, Adad SJ, Hazarabedian de Souza MA, Macedo Barcelos AC, Sarreta Terra AP, Murta EF. Increased frequency of bacterial vaginosis and Chlamydia trachomatis in pregnant women with human papillomavirus infection. Gynecol Obstet Invest. 2004;58(4):189-93.

69. Westhoff C, Gentile G, Lee J, Zacur H, Helbig D. Predictors of ovarian steroid secretion in reproductive-age women. Am J Epidemiol. 1996;144(4):381-8.

70. Sobel JD. Vulvovaginal candidosis. Lancet. 2007;369(9577):1961-71.

71. Pavlova SI, Tao L. Induction of vaginal Lactobacillus phages by the cigarette smoke chemical benzo[a]pyrene diol epoxide. Mutat Res. 2000;466(1):57-62.

72. Antonio MA, Hawes SE, Hillier SL. The identification of vaginal Lactobacillus species and the demographic and microbiologic characteristics of women colonized by these species. J Infect Dis. 1999;180(6):1950-6.

\section{Submit your next manuscript to BioMed Central and we will help you at every step:}

- We accept pre-submission inquiries

- Our selector tool helps you to find the most relevant journal

- We provide round the clock customer support

- Convenient online submission

- Thorough peer review

- Inclusion in PubMed and all major indexing services

- Maximum visibility for your research

Submit your manuscript at www.biomedcentral.com/submit
) Biomed Central 